\title{
WERDC
}

\section{Optimization of LC-MS/MS Parameters for Analysis of Per- and Polyfluoroalkyl Substances (PFAS)}

by Lee Moores, Ashley Kimble, Garrett George, David Henderson, Bobbi Stromer, Rebecca Crouch, Lauren Soblosky, Jared Smith, Anthony Bednar

PURPOSE: Integrate US Environmental Protection Agency (USEPA) Method 537 on current instrumentation to provide per- and polyfluoroalkyl substances (PFAS) analytical capabilities for the US Army Engineer Research and Development Center (ERDC), US Army Corps of Engineers (USACE) and the Department of Defense (DoD).

BACKGROUND: Per- and polyfluoroalkyl substances, collectively known as PFAS, are synthetic molecules used for myriad purposes in industrial, military, and consumer products. The compounds are persistent in the environment due to the very strong $\mathrm{C}-\mathrm{F}^{1}$ bond and may exhibit carcinogenic, teratogenic, and bioaccumulative properties (Ding and Peijnenburg 2013; Gorrochategui et al. 2014). Due to concerns based on these properties, advisory limits have been set at a total concentration of $70 \mathrm{ng} / \mathrm{L}^{2}$ as a sum of each analyte's individual concentration. Of particular interest for the DoD is the use of PFAS in firefighting applications as a major component of aqueous film-forming foam (AFFF), used extensively in training exercises and emergency fire response.

Materials and Methods. The 14 analytes in USEPA 537 were purchased as an analytical standard with a stock concentration of $2 \mu \mathrm{g} / \mathrm{mL}$, and the isotopically labeled internal standards (IS) and surrogates (SUR) were purchased from Wellington Laboratories (Guelph, Ontario, Canada), as listed in table 1. Ammonium acetate (99.99\%) was purchased from Sigma Aldrich (St. Louis, Missouri). Optima (mass spectrometry, or MS) grade water and methanol for use as diluents and highperformance liquid chromatography (HPLC) mobile phase were purchased from Fisher Scientific (Hampton, New Hampshire). All dilutions and samples were made and stored in polypropylene containers. HyperSep Retention PEP solid-phase extraction (SPE) cartridges were purchased from Thermo Scientific (Waltham, Masssachusetts).

1. For a full list of the spelled-out forms of the chemical elements used in this document, please refer to US Government Publishing Office Style Manual, 31st ed. (Washington, DC: US Government Publishing Office, 2016), 265, https://www.govinfo.gov/content/pkg/GPO-STYLEMANUAL-2016/pdf/GPO-STYLEMANUAL-2016.pdf.

2. For a full list of the spelled-out forms of the units of measure used in this document, please refer to US Government Publishing Office Style Manual, 31st ed. (Washington, DC: US Government Publishing Office, 2016), 248-52, https://www.govinfo.gov/content/pkg/GPO-STYLEMANUAL-2016/pdf/GPO-STYLEMANUAL2016.pdf. 


\begin{tabular}{|c|c|c|c|c|}
\hline Chemical & Acronym & $\begin{array}{l}\text { Precursor } \\
\text { ion }(m / z)\end{array}$ & $\begin{array}{l}\text { Product } \\
\text { ion }(\mathrm{m} / \mathrm{z})\end{array}$ & $\begin{array}{c}\text { Collision } \\
\text { energy } \\
\text { (V) }\end{array}$ \\
\hline perfluorobutanesulfonic acid & PFBS & 298.94299 & 79.9569 & 40 \\
\hline perfluorohexanenoic acid & PFHxA & 312.97281 & 268.9829 & 12 \\
\hline${ }^{13} \mathrm{C}_{2}$-perfluorohexanoic acid & ${ }^{13} \mathrm{C}_{2}$-PFHxA & 314.97856 & 269.9866 & 10 \\
\hline perfluorohepatnoic acid & PFHpA & 362.96962 & 318.9798 & 10 \\
\hline perfluorohexanesulfonic acid & PFHxS & 398.9366 & 79.9569 & 60 \\
\hline Perfluorooctanoic acid & PFOA & 412.96643 & 368.9767 & 10 \\
\hline${ }^{13} \mathrm{C}_{2}$-perfluoroocatnoic acid & ${ }^{13} \mathrm{C}_{2}$-PFOA & 502.94495 & 79.9569 & 10 \\
\hline perfluorononanoic acid & PFNA & 462.96323 & 418.9736 & 18 \\
\hline perfluorooctanesulfonic acid & PFOS & 498.93022 & 79.9569 & 40 \\
\hline${ }^{13} \mathrm{C}_{2}$-perfluorooctanesulfonic acid & ${ }^{13} \mathrm{C}_{2}$-PFOS & 502.94495 & 79.9570 & 40 \\
\hline perfluorodecanoic acid & PFDA & 512.96004 & 468.9702 & 11 \\
\hline${ }^{13} \mathrm{C}_{2}$-perfluorodecanoic acid & ${ }^{13} \mathrm{C}_{2}$-PFDA & 514.96790 & 469.9739 & 10 \\
\hline perfluoroundecanoic acid & PFUnA & 562.95684 & 518.9674 & 10 \\
\hline N-methyl perfluorooctanesulfonamidoacetic acid & NMeFOSAA & 569.96733 & 418.9735 & 18 \\
\hline $\mathrm{d}_{3}$-N-methyl perfluorooctanesulfonamidoacetic acid & $\mathrm{d}_{3}$-NMeFOSAA & 572.98730 & 418.9740 & 10 \\
\hline N-ethyl perfluorooctanesulfonamidoacetic acid & NEtFOSAA & 583.98298 & 418.9735 & 18 \\
\hline $\mathrm{d}_{5}$-N-ethyl perfluorooctanesulfonamidoacetic acid & $\mathrm{d}_{5}$-NEtFOSAA & 589.01575 & 418.9737 & 20 \\
\hline perfluorododecanoic acid & PFDoA & 612.95365 & 568.9644 & 10 \\
\hline perfluorotridecanoic acid & PFTrDA & 662.95046 & 618.96141 & 10 \\
\hline pefluorotetradecanoic acid & PFTA & 712.94726 & 668.9584 & 10 \\
\hline
\end{tabular}

Samples of PFAS were analyzed on a ThermoFisher HPLC-MS/MS (Vanquish LC, Orbitrap High Resolution Accurate Mass-Mass Spectrometer, or HRAM-MS) equipped with a Hypersil C8 delay column ( 3 × $50 \mathrm{~mm}$, particle size $5 \mu \mathrm{m}$, Thermo Scientific) to ensure PFAS leached from parts intrinsic to the system from eluting with sample or standard PFAS. A $50 \mu \mathrm{L}$ aliquot of standards or unknown samples was separated across a Hypersil GOLD aQ C-18 analytical HPLC column $\left(2.1 \times 150 \mathrm{~mm}, 3 \mu \mathrm{m}\right.$, Thermo Scientific) maintained at $40^{\circ} \mathrm{C}$ during chromatographic separations. A gradient mobile phase pumped at $0.300 \mathrm{~mL} \mathrm{~min}^{-1}$ (A: $20 \mathrm{mM}$ ammonium acetate; B: LC-MS methanol) through PEEK tubing with the gradient described in table 2 . The samples were analyzed in parallel reaction monitoring mode (PRM) with parameters described in table 2. Optimized collision energies for each compound and their precursor and product ions are listed in table 1.

Calibration curves were generated by dilution of analytical standards with 96:4 MeOH:H $2 \mathrm{O}(\mathrm{v} / \mathrm{v})$ from $156 \mathrm{ng} / \mathrm{L}$ to $20 \mu \mathrm{g} / \mathrm{L}$ and injected using the above described instrument parameters. Each calibration standard was spiked with isotopically labeled PFAS IS to final concentrations of 1, 3, and $4 \mu \mathrm{g} / \mathrm{L}$ for ${ }^{13} \mathrm{C}_{2}$-PFOA, ${ }^{13} \mathrm{C}_{2} \mathrm{PFOS}$, and $\mathrm{d}_{3}$-NMeFOSAA, respectively. Individual calibration points are reported as a ratio of the peak areas of PFAS/IS to eliminate any bias due to fluctuations of the ionization efficiency. The average percent relative standard deviation for the standards and surrogates was found to be $6.8 \%$ for 13 samples. 


\begin{tabular}{|c|c|c|c|c|c|c|}
\hline \multicolumn{3}{|c|}{ LC Gradient Parameters } & \multicolumn{4}{|l|}{ MS Parameters } \\
\hline time & $\% \mathrm{~A}$ & $\% \mathrm{~B}$ & probe position & $\mathrm{C}$ & auxilary gas temperature & $325^{\circ} \mathrm{C}$ \\
\hline 0 & 70 & 30 & voltage & $2.5 \mathrm{kV}$ & $\mathrm{m} / \mathrm{z}$ range & $70-740$ \\
\hline 1 & 70 & 30 & sheath gas & $25 \mathrm{AU}$ & resolution & 35,000 \\
\hline 25 & 10 & 90 & auxilary gas & $8 \mathrm{AU}$ & microscans & 5 \\
\hline 27.5 & 10 & 90 & $\begin{array}{l}\text { capillary } \\
\text { temperature }\end{array}$ & $300{ }^{\circ} \mathrm{C}$ & $\begin{array}{l}\text { automatic gain control } \\
\text { target }\end{array}$ & 100,000 \\
\hline 30 & 70 & 30 & S-lens RF level & $50 \mathrm{AU}$ & max injection time & $100 \mathrm{~ms}$ \\
\hline
\end{tabular}

Solid phase extraction cartridges were conditioned with $15 \mathrm{~mL}$ of $\mathrm{MeOH}$ and equilibrated with 18 $\mathrm{mL}$ of MS grade water. To each conditioned cartridge was added 2-3 mL of MS grade water to prevent drying before loading $250 \mathrm{~mL}$ of sample fortified with $10 \mu \mathrm{L}$ of 1,1 , and $4 \mu \mathrm{g} / \mathrm{L}$ of ${ }^{13} \mathrm{C}_{2^{-}}$ PFHxA, ${ }_{31} \mathrm{C}^{2}$-PFDA, and $\mathrm{d}_{5}$-NEtFOSAA, respectively, directly from sample bottles using prerinsed polyethylene transfer tubes. All samples were loaded at a flow rate of approximately 10$15 \mathrm{~mL} / \mathrm{min}$. Once full samples were loaded onto SPE cartridges, sample bottles were rinsed with two $7.5 \mathrm{~mL}$ aliquots of MS grade water and transferred through the transfer tubes to load any residual sample onto cartridges. Cartridges were then dried under vacuum for five minutes at room temperature on the manifold. After drying, analyte elution was achieved by rinsing the sample bottles with two $4 \mathrm{~mL}$ aliquots of $\mathrm{MeOH}$ through the transfer tubes and collected in a $15 \mathrm{~mL} \mathrm{HDPE}$ centrifuge tube. After collection of the eluent, methanol extracts were evaporated to dryness under nitrogen in a $60^{\circ} \mathrm{C}$ water bath. Once dried, extracts were reconstituted to $1 \mathrm{~mL}$ using 96:4 (v/v) $\mathrm{MeOH}$ :water containing the same concentration of IS as the calibration curve.

Results and Discussion. Separation of the analytes via HPLC was achieved with the above described method (figure 1). There are some coeluting compounds, PFNA and PFOS, and NetFOSAA and PFUnA; however, the molecules have different precursor and product ions (table 1 , above) allowing for concomitant detection and quantification by the mass spectrometer.

Injection of calibration standards resulted in linear calibration responses and are summarized in table 3, along with representative calibration curves for PFOA and PFOS in figure 2. The $156 \mathrm{ng} / \mathrm{L}$ standard for NMeFOSAA and the $312 \mathrm{ng} / \mathrm{L}$ standard for NEtFOSAA were not observed, and the $156 \mathrm{ng} / \mathrm{L}$ standard for PFBS returned a calculated concentration outside of the $\pm 50 \%$ tolerance for standards below the proposed minimum reporting limit (MRL, detailed below). 


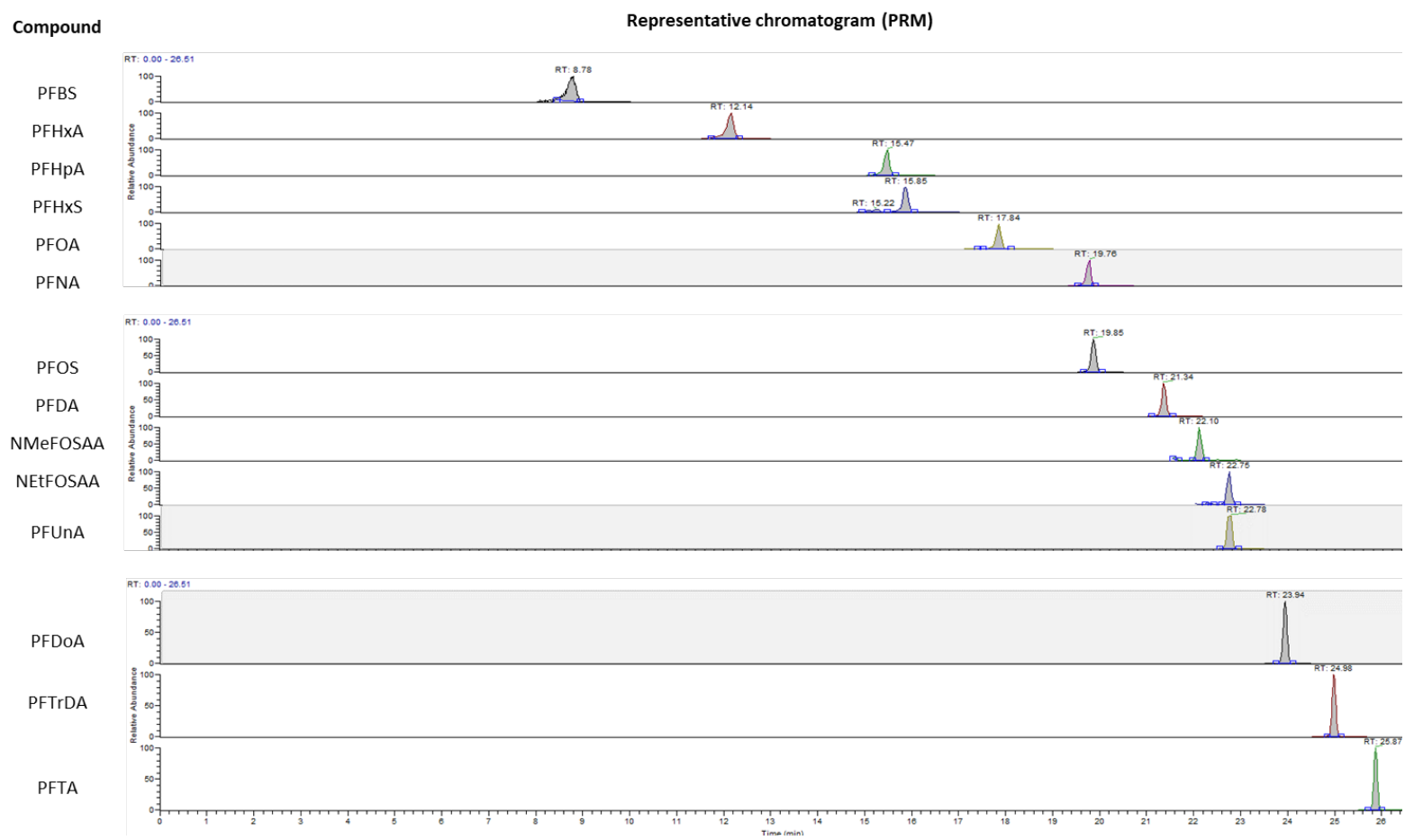

Figure 1. Representative chromatogram of $2.5 \mu \mathrm{g} / \mathrm{L}$ PFAS standard showing adequate separation for the analysis of PFAS compounds.

Table 3. PFAS Calibration Curves.

\begin{tabular}{|l||l|l|l||l||}
\hline PFAS & equation & $\mathbf{R}^{2}$ & $\begin{array}{l}\text { low } \\
\text { concentration } \\
\text { (ng/L) }\end{array}$ & $\begin{array}{l}\text { error in } \\
\text { calculated } \\
\text { concentration }\end{array}$ \\
\hline \hline PFBS & $0.2151 \mathrm{x}$ & 0.9986 & 312 & 44 \\
\hline PFHxA & $0.3898 \mathrm{x}$ & 0.9991 & 156 & 28 \\
\hline PFHpA & $0.7515 \mathrm{x}$ & 0.9996 & 156 & 16 \\
\hline PFHxS & $0.9808 \mathrm{x}$ & 0.9997 & 156 & 7 \\
\hline PFOA & $1.0282 \mathrm{x}$ & 0.9994 & 156 & 2 \\
\hline PFNA & $0.2323 \mathrm{x}$ & 0.9966 & 156 & 26 \\
\hline PFOS & $0.2676 \mathrm{x}$ & 0.9992 & 156 & 5 \\
\hline PFDA & $0.7272 \mathrm{x}$ & 0.9982 & 156 & 1 \\
\hline NMeFOSAA & $0.8686 \mathrm{x}$ & 0.9995 & 312 & 24 \\
\hline NEtFOSAA & $0.8999 \mathrm{x}$ & 0.9994 & 625 & 14 \\
\hline PFUnA & $5.7424 \mathrm{x}$ & 0.9974 & 156 & 6 \\
\hline PFDoA & $7.0131 \mathrm{x}$ & 0.9971 & 156 & 7 \\
\hline PFTrA & $6.0424 \mathrm{x}$ & 0.9987 & 156 & 22 \\
\hline PFTA & $6.3090 \mathrm{x}$ & 0.9993 & 156 & 27 \\
\hline \hline
\end{tabular}



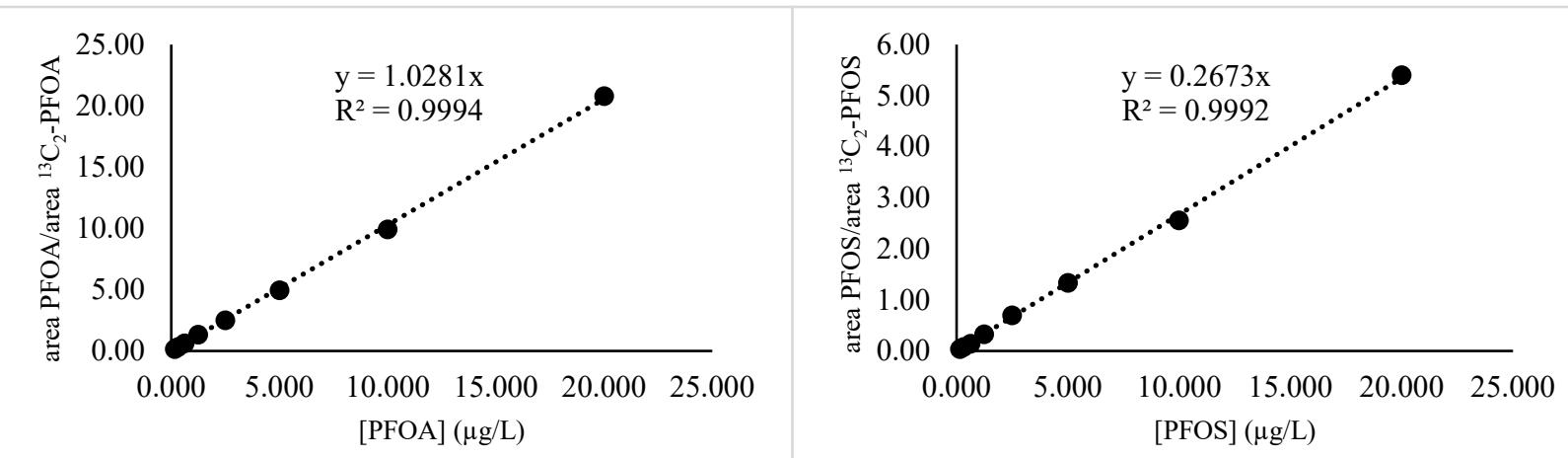

Figure 2. Calibration curves for PFOA and PFOS, respectively, from left to right.

Fortification of laboratory blank water samples with PFAS standards and subsequent analysis following SPE concentration allowed for the determination of MRLs for 12 of the 14 compounds. These results are summarized in table 4 . The extraction procedure was precise, meeting the goal of $\pm 20 \%$ RSD for each of the analytes; however, in each case the percent recovery was less than $100 \%(64.8-95.7 \%)$. For two of the compounds, NEtFOSAA and PFTA, the recoveries fell outside of the allowable window of $\pm 30 \%$ for the method validation; yet their respective calibration curves were still linear to concentrations of 625 and $156 \mathrm{ng} / \mathrm{L}$, respectively. The analytical method was further explored by calculating the half range for the prediction interval of results (HRPIR) and the upper and lower limits of the range based on the standard deviation for each analyte sample set and the number of samples tested (n).

Table 4. Method reporting limits of PFAS compounds.

\begin{tabular}{|c|c|c|c|c|c|c|c|c|c|c|}
\hline PFAS & $n$ & \begin{tabular}{|l} 
Fortified \\
[PFAS] \\
(ng/L)
\end{tabular} & $\begin{array}{l}\text { Extracted } \\
\text { [PFAS] } \\
(\mu \mathrm{g} / \mathrm{L})\end{array}$ & $\begin{array}{l}\text { Avg. } \\
\text { Measured } \\
\text { [PFAS] } \\
(\mu g / L)\end{array}$ & $\begin{array}{l}\text { Std. } \\
\text { dev. }\end{array}$ & \%RSD & $\begin{array}{l}\text { avg. } \% \\
\text { recovery }\end{array}$ & HRPIR & $\begin{array}{l}\text { Upper } \\
\text { PIR Limit } \\
\text { (\%) }\end{array}$ & $\begin{array}{l}\text { Lower } \\
\text { PIR Limit } \\
\text { (\%) }\end{array}$ \\
\hline PFBS & 7 & 750 & 10.5 & 9.42 & 0.99 & 10.54 & 89.7 & 3.93 & 127.2 & 52.3 \\
\hline PFHxA & 7 & 750 & 10.5 & 7.81 & 0.47 & 5.98 & 74.4 & 1.85 & 92.0 & 56.7 \\
\hline PFHpA & 7 & 750 & 10.5 & 8.60 & 0.41 & 4.76 & 82.0 & 1.62 & 97.4 & 66.5 \\
\hline PFHxS & 7 & 750 & 10.5 & 9.49 & 0.44 & 4.67 & 90.4 & 1.76 & 107.2 & 73.7 \\
\hline PFOA & 7 & 750 & \begin{tabular}{|l|}
10.5 \\
\end{tabular} & 8.52 & 0.37 & 4.31 & 81.1 & 1.46 & 95.0 & 67.2 \\
\hline PFOS & 7 & 750 & 10.5 & 10.05 & 0.55 & 5.5 & 95.7 & 2.19 & 116.5 & 74.8 \\
\hline PFNA & 7 & 750 & 10.5 & 8.64 & 0.36 & 4.21 & 82.3 & 1.44 & 96.0 & 68.6 \\
\hline PFDA & 7 & 750 & 10.5 & 8.73 & 0.35 & 4.01 & 83.2 & 1.39 & 96.4 & 70.0 \\
\hline NMeFOSAA & 7 & 750 & 10.5 & 7.78 & 0.61 & 7.79 & 74.1 & 2.40 & 96.9 & 51.2 \\
\hline PFUnA & 7 & 750 & 10.5 & 9.08 & 0.62 & 6.84 & 86.5 & 2.46 & 110 & 63.1 \\
\hline NEtFOSAA & 7 & 750 & 10.5 & 6.80 & 0.60 & 8.85 & 64.8 & 2.39 & 87.5 & 42.1 \\
\hline PFDoA & 7 & 750 & 10.5 & 8.20 & 0.47 & 5.69 & 78.1 & 1.85 & 95.7 & 60.5 \\
\hline PFTrDA & 7 & 750 & 10.5 & 8.58 & 0.45 & 5.25 & 81.7 & 1.78 & 98.7 & 64.7 \\
\hline PFTA & 7 & 750 & 10.5 & 6.84 & 0.56 & 8.22 & 65.1 & 2.23 & 86.3 & 43.9 \\
\hline
\end{tabular}

SUMMARY: The USEPA Method 537 was implemented on current analytical instrumentation in place at the ERDC Environmental Laboratory (ERDC-EL) Environmental Chemistry Branch (EPC) to analyze aqueous samples containing PFAS. Calibrations were linear from $156 \mathrm{ng} / \mathrm{L}-20 \mu \mathrm{g} / \mathrm{L}$ for 11 of the 14 compounds, with the exception of PFBS (312 ng/L), NMeFOSAA (312 ng/L), and 
NEtFOSAA (625 ng/L). MRL's of $750 \mathrm{ng} / \mathrm{L}$ were determined for 12 of 14 compounds. NEtFOSAA and PFTA were the only analytes with slightly higher calculated MRLs. For NEtFOSAA, this slighter higher MRL is likely due to instrumentation limitations, as this particular compound was not observed in the calibration curve below $625 \mathrm{ng} / \mathrm{L}$; however, the PFTA gave satisfactory results to $312 \mathrm{ng} / \mathrm{L}$ in the calibration curves, and therefore the poor performance observed is likely due to poor recovery from SPE cartridges. Further optimization of the method is currently underway to achieve MRL values below the USEPA advisory limit of $70 \mathrm{ng} / \mathrm{L}$ for each of the compounds. These optimizations include both instrumental parameters as well as sample extraction and preconcentration (SPE) procedures.

Similar method development and validation studies are currently underway to evaluate complementary analytical capabilities on a newly acquired HPLC triple quadrupole mass spectrometer (QqQ, Agilent, G6495B), anticipated to yield detection limits in the range of $1 \mathrm{ng} / \mathrm{L}$ and MRL values in the $10 \mathrm{ng} / \mathrm{L}$ ranges. Additionally, method modification and refinement is needed for application of these techniques to more complex natural matrices, including complex aqueous, soil or sediment, and tissue samples. Use of the HRAM MS mode in environmental fate, remediation, and degradation studies should allow detection and identification of degradation products.

Future work on PFAS degradation and remediation efforts may also employ other advanced analytical capabilities available within ERDC-EL. For example, volatile PFAS degradation products may also be detected and identified using thermal desorption gas chromatography-mass spectrometry (TD-GC-MS). Alternatively, ion chromatography (IC) could be employed for determination of defluorination efficiency. Additionally, chemical structure determination of parent and daughter PFAS compounds can potentially be elucidated using advanced ${ }^{1} \mathrm{H},{ }^{13} \mathrm{C}$, and ${ }^{19} \mathrm{~F}$ nuclear magnetic resonance (NMR) spectroscopy.

ADDITIONAL INFORMATION: This technical note was prepared by Dr. Lee C. Moores, research chemist, Environmental Laboratory (EL), US Army Engineer Research and Development Center (ERDC) (Lee.C.Moores@usace.army.mil), Dr. Ashely Kimble, research chemist, EL, ERDC, Dr. Rebecca Crouch, research chemist, EL, ERDC, Mr. Garrett George, research chemist, EL, ERDC, Mr. David Henderson, research biologist, EL, ERDC, Dr. Bobbi Stromer, research chemist, EL, ERDC, Dr. Lauren Soblosky, senior scientist I, HX5, Mr. Jared Smith, research chemist, EL, ERDC, and Dr. Anthony Bednar, research chemist, EL, ERDC (Anthony.J.Bednar@usace.army.mil).

POINTS OF CONTACT: For additional information, contact Dr. Lee Moores or Dr. Anthony Bednar. This technical note should be cited as follows:

Moores, Lee, Ashley Kimble, Garrett George, David Henderson, Bobbi Stromer, Rebecca Crouch, Lauren Soblosky, Jared Smith, and Anthony Bednar. 2020. Optimization of LCMS/MS Parameters for Analysis of Per- and Polyfluoroalkyl Substances (PFAS). ERDC EL Technical Notes (ERDC/EL TN-20-4). Vicksburg, MS: US Army Engineer Research and Development Center. 


\section{REFERENCES}

Ding, G.; Peijnenburg, W. Physicochemical Properties and Aquatic Toxicity of Poly- and Perfluorinated Compounds. Crit. Rev. Environ. Sci. Technol. 2013, 43, 598-678.

EPA Method 537. Determination of Selected Perfluorinated Alkyl Acids in Drinking Water by Solid Phase Extraction and Liquid Chromatography/Tandem Mass Spectrometry (LC/MS/MS). EPA/600/R-08/092. 2009, Version 1.1.

Gorrochategui, E.; Lacorte, S.; Tauler, R.; Martin, F.L. Perfluorinated Substance Effects in Xenopus laevis A6 Kidney Epithelial Cells Determined by ATR-FTIR Spectroscopy and Chemometric Analysis. Che. Res. Toxicol. 2016, 29, 924-932.

NOTE: The contents of this technical note are not to be used for advertising, publication, or promotional purposes. Citation of trade names does not constitute an official endorsement or approval of the use of such products. 